\title{
Comparison of urinary parameters, biomarkers, and outcome of childhood systemic lupus erythematosus early onset- lupus nephritis
}

Daniele Faria Miguel ${ }^{1}$, Maria Teresa Terreri ${ }^{2}$, Rosa Maria Rodrigues Pereira ${ }^{3}$, Eloisa Bonfá ${ }^{3}$, Clovis Artur Almeida Silva ${ }^{4}$, José Eduardo Corrente ${ }^{5}$, Claudia Saad Magalhaes ${ }^{6 *}$ and for the Brazilian Childhood-onset Systemic Lupus Erythematosus Group

\begin{abstract}
Background: Urinary parameters, anti-dsDNA antibodies and complement tests were explored in patients with childhood-Systemic Lupus Erythematosus (CSLE) early-onset lupus nephritis (ELN) from a large multicenter cohort study.

Methods: Clinical and laboratory features of CSLE cases with kidney involvement at presentation, were reviewed. Disease activity parameters including SLEDAI- $2 \mathrm{~K}$ scores and major organ involvement at onset and follow up, with accrued damage scored by SLICC-DI, during last follow up, were compared with those without kidney involvement. Autoantibodies, renal function and complement tests were determined by standard methods. Subjects were grouped by presence or absence of ELN.

Results: Out of the 846 subjects enrolled, mean age 11.6 (SD 3.6) years; 427 (50.5\%) had ELN. There was no significant difference in the ELN proportion, according to onset age, but ELN frequency was significantly higher in non-Caucasians $(p=0.03)$. Hematuria, pyuria, urine casts, 24-h proteinuria and arterial hypertension at baseline, all had significant association with ELN outcome $(p<0.001)$. With a similar follow up time, there were significantly higher SLICC-DI damage scores during last follow up visit $(p=0.004)$ and also higher death rates $(p<0.0001)$ in those with ELN. Low C3 (chi-square test, $p=0.01$ ), but not C3 levels associated significantly with ELN. High antidsDNA antibody levels were associated with ELN ( $p<0.0001)$, but anti-Sm, anti-RNP, anti-Ro, anti-La antibodies were not associated. Low C4, C4 levels, low CH50 and CH50 values had no significant association. High erythrocyte sedimentation rate (ESR) was associated with the absence of ELN $(p=0.02)$.
\end{abstract}

Conclusion: The frequency of ELN was 50\%, resulting in higher morbidity and mortality compared to those without ELN. The urinary parameters, positive anti-dsDNA and low C3 are reliable for discriminating ELN.

Keywords: Anti-dsDNA antibodies, Childhood-onset systemic lupus erythematosus, Complement, C3, C4, Lupus nephritis

\footnotetext{
* Correspondence: claudia.saad@unesp.br

${ }^{6}$ Pediatric Rheumatology Division, Faculdade de Medicina de Botucatu,

Universidade Estadual Paulista (UNESP), Botucatu, Brazil

Full list of author information is available at the end of the article
}

(c) The Author(s). 2020 Open Access This article is distributed under the terms of the Creative Commons Attribution 4.0 International License (http://creativecommons.org/licenses/by/4.0/), which permits unrestricted use, distribution, and reproduction in any medium, provided you give appropriate credit to the original author(s) and the source, provide a link to the Creative Commons license, and indicate if changes were made. The Creative Commons Public Domain Dedication waiver (http://creativecommons.org/publicdomain/zero/1.0/) applies to the data made available in this article, unless otherwise stated. 


\section{Background}

Childhood systemic lupus erythematosus (cSLE) accounts for nearly $10-15 \%$ of all cases of SLE. It affects multiple organ systems including the kidneys, central nervous system, hematopoietic cells and skin [1] .

Lupus nephritis has been identified in $20-75 \%$ of childhood patients, indicating the worse prognosis when compared to adult patients [2-6]. However, most of the reported series evaluated lupus nephritis along the disease course. Only two series correlated silent lupus nephritis identified by renal biopsies at disease onset with serum biomarkers, including products of complement activation, as $\mathrm{C} 3$ and $\mathrm{C} 4$ levels [3, 7].. Ethnicity is one of the parameter associated to disease severity and systemic involvement [7] and there was no similar study in Latin America population. Therefore, we addressed the issue, exploring urinary parameters, renal function, anti dsDNA antibodies and complement tests in patients with childhood-Systemic Lupus Erythematosus (cSLE) and early-onset lupus nephritis (ELN), from a large multicenter national cohort study.

\section{Methods}

A large multicentric database including historical cohorts of cSLE cases, classified by the American College of Rheumatology (ACR) 1997 criteria, in 10 of the Brazilian cSLE Study Group centers, from 2013 to 2016, was analyzed for secondary data [8]. Parameters of cSLE activity were SLE Disease Activity Index 2000 (SLEDAI$2 \mathrm{~K})$ scores at disease onset [9], major organ involvement such as glomerulonephritis, vasculitis, neuropsychiatric lupus, hematologic and cardio-vascular involvement and disease damage scores by Systemic Lupus International Collaborating Clinics/ACR-Damage Index (SLICC/DI) [10], at the last follow up visit.

Laboratory data, including antibody tests, urinary parameters and complement tests were obtained using standard methods in each laboratory of participating centres. Renal involvement status was defined according to pediatric definitions and guidelines [11, 12], as estimated by the physicians in the retrospective data collection. Glomerulonephritis was considered if either urine leukocytes, red blood cells, casts or renal function impairment above the normal range were present. Acute renal failure was defined as any sudden increase of serum creatinine above $2 \mathrm{mg} / \mathrm{dl}$. Chronic renal failure was established with glomerular filtration rate lower than $60 \mathrm{ml} / \mathrm{min} / 1.73 \mathrm{~m} 2$ of body surface, with or without any structural or functional damage, observed by abnormal biomarker or imaging, and occurring beyond 3 month of duration.

Initial c-SLE renal and extra-renal manifestations, including events recorded during the first six months after the diagnosis, the presence of arterial hypertension, abnormal urinalysis results, 24-h urinary protein excretion, renal function, acute and chronic renal failure status were used for comparison of the groups of cSLE with and without ELN. C3, C4, CH50, antinuclear antibodies (ANA), anti-double-stranded DNA (anti-dsDNA), anti-Sm, RNP, Ro/SSA and La/SSB tests results were also compared [8]. The clinical diagnosis of ELN required the presence of active urinary sediment based on SLEDAI-2 K criteria by Gladman et al. [9] during the first six month of the diagnosis. We selected the SLEDAI-2 K tool in order to standardize comparison of nephritis activity over time. Renal biopsy and histopathology evaluations by light microscopy and immunofluorescence, were performed independently, in each of the centres, and evaluated by local pathologists, classifying renal lesions by the World Health Organization (WHO) criteria or 2004 ISN/RPS criteria, scoring active and chronic lesions [11]. Subjects were classified according to the presence or absence of ELN, estimated by either clinical or biopsy findings.

Descriptive and parametric statistics, T-test and chisquare, were used for comparison of the groups of cSLE with and without ELN, at disease onset. The statistics tests were performed using SAS software v. 9.2 and values were considered significant if $p<0.05$.

\section{Results}

Out of 852 subjects selected in the primary study from Gomes et al. [8], 846 with mean age of 11.6 (SD 3.6) years, with a comprehensive clinical assessment, were enrolled. Of those, 427 (50.5\%) presented early-onset ELN and $419(49,5 \%)$ did not present with ELN. Renal biopsy was performed in 228 of the cases, but only 181 were classified according to WHO criteria or 2004 ISN/ RPS criteria, in addition to standard histopathology parameters [13]. Of those with renal biopsy, histopathology classification by WHO-2004 resulted in the proportion of 11 (6\%) class I, 45 (25\%) class II, 25 (14\%) class III, 76 (42\%) class IV, 21 (11\%) class V and 3 (2\%) class VI.

Table 1 illustrates demographic data, clinical features, laboratory, urinary parameters and outcome, in cSLE patients with and without ELN. No significant difference was found between male and female subjects, and no significant difference was found in each group of onset age, $<6$ years, 6-12 and $>12$ years. But, there was a significant difference related to the ethnic background. ELN frequency was significantly higher in non-Caucasian $(p=0.03)$. For ethnic classification, 20 subjects had missing data. Renal parameters, as $24 \mathrm{~h}$-proteinuria, hematuria, pyuria, urine casts and arterial hypertension were compared, resulting in significant difference for those with $\operatorname{ELN}(p<0.001)$, as well as presentation with acute renal failure $(\mathrm{p}<0.001)$ and chronic renal failure $(p<0.0002)$. Low complement, defined by low $\mathrm{C} 3, \mathrm{C} 4$ or $\mathrm{CH} 50$ activity, was found in nearly $70 \%$ of those tested. Low C3 $(p=0.01)$ but not C3 levels, was associated significantly with ELN. Low C4, C4 levels or 
Table 1 - Demographic and clinical features, laboratory parameters, disease activity, damage scores and death rates comparison in childhood-onset Systemic Lupus Erythematosus (c-SLE) patients with and without early onset lupus nephritis (ELN)

\begin{tabular}{|c|c|c|c|c|c|}
\hline Variables & $\begin{array}{l}n \text { of cases } \\
427\end{array}$ & CSLE with ELN & $\begin{array}{l}n \text { of cases } \\
419\end{array}$ & cSLE without ELN & $p$-Value \\
\hline Onset age (y) & & $11.6 \pm 2.8$ & & $11.7 \pm 3.2$ & 0.65 \\
\hline $0-6$ y $n(\%)$ & & $17(3.9)$ & & $21(5)$ & 0.74 \\
\hline $6-12$ y $n(\%)$ & & $206(48.2)$ & & $196(46.7)$ & 0.74 \\
\hline$>12$ y $n(\%)$ & & $198(46.3)$ & & $194(46.3)$ & 0.74 \\
\hline Female $n(\%)$ & & $357(83.6)$ & & $360(86)$ & 0.18 \\
\hline Caucasian $n(\%)$ & 407 & $274(67.3)$ & 405 & $304(72.5)$ & $0.03^{*}$ \\
\hline Non-Caucasian $n(\%)$ & 407 & $133(32.7)$ & 405 & $101(24.9)$ & $0.03^{*}$ \\
\hline SLEDAI-2 K (mean, SD) median & & $(20 \pm 8) 20$ & & $(12 \pm 7) 11$ & $<0.001^{*}$ \\
\hline Acute renal failure (ARF) $n(\%)$ & & $94(22)$ & & 0 & $<0.001^{*}$ \\
\hline Chronic renal failure (CRF) $n(\%)$ & & $17(4)$ & & 0 & $0.0002^{*}$ \\
\hline Arterial hypertension n (\%) & & $181(42.3)$ & & $18(4.2)$ & $<0.001^{*}$ \\
\hline Haematuria $n(\%)$ & & $309(72.3)$ & & $56(13.36)$ & $<0.001^{*}$ \\
\hline Pyuria $n(\%)$ & & $223(52.2)$ & & $49(11.7)$ & $<0.001^{*}$ \\
\hline Urine Casts $n(\%)$ & & $153(35.8)$ & & $21(5)$ & $<0.001^{*}$ \\
\hline Proteinuria $n(\%)$ & & $191(44.7)$ & & $67(16)$ & $<0.001^{*}$ \\
\hline $24 \mathrm{~h}$ Proteinuria (g/day) (mean, SD) & 191 & $(1.5 \pm 2.9)$ & 225 & $(0.12 \pm 0.18)$ & $<0.001^{*}$ \\
\hline Low C3 n (\%) & 301 & $198(65.7)$ & 303 & $174(57.4)$ & $0.01^{*}$ \\
\hline Low C4 n (\%) & 265 & $183(69)$ & 280 & $183(65.3)$ & 0.07 \\
\hline Low CH50 n (\%) & 91 & $62(68.1)$ & 54 & $35(65)$ & 0.07 \\
\hline C3 (mg/dl) (mean, SD) & 301 & $(60 \pm 36)$ & 303 & $(73 \pm 38)$ & 0.05 \\
\hline C4 (mg/dl) (mean, SD) & 265 & $(12 \pm 14)$ & 280 & $(12 \pm 10)$ & 0.18 \\
\hline CH50 (U/ml) (mean, SD) & 91 & $(87 \pm 79)$ & 54 & $(110 \pm 84)$ & 0.07 \\
\hline ESR mm/h (mean, SD) & 343 & $(42 \pm 35)$ & 346 & $(49 \pm 32)$ & $0.02^{*}$ \\
\hline CRP mg\% (mean, SD) & 179 & $(5 \pm 7)$ & 217 & $(4 \pm 6)$ & 0.49 \\
\hline Anti-dsDNA antibodies $n(\%)$ & 381 & $286(75)$ & 397 & $253(63.7)$ & $0.0001^{*}$ \\
\hline Anti-Sm antibodies $n(\%)$ & 312 & $106(34)$ & 317 & $124(39)$ & 0.14 \\
\hline Anti-RNP antibodies $n(\%)$ & 295 & $73(24.7)$ & 298 & $79(26.5)$ & 0.46 \\
\hline Anti-Ro/SSA antibodies $n(\%)$ & 280 & $88(31.4)$ & 298 & $93(31.2)$ & 0.88 \\
\hline Anti-La/SSB antibodies $n(\%)$ & 274 & $37(13.5)$ & 290 & $41(14)$ & 0.90 \\
\hline SLICC/DI (range) median & & (0-9) 1 & & $(0-3) 0$ & $0.004^{*}$ \\
\hline Disease duration (y) (mean, SD) & & $(4.2 \pm 3.6)$ & & $(4.2 \pm 3.5)$ & 0.80 \\
\hline Death n (\%) & 404 & $99(24)$ & 419 & $18(4)$ & $<0.0001^{*}$ \\
\hline
\end{tabular}

CH50 activity had no significant difference in the same comparison (Table 1).

Positive anti-dsDNA antibody test was associated with $\operatorname{ELN}(p<0.0001)$, but all other autoantibodies, such as positive anti-Sm, anti-RNP, anti-Ro/SSA, anti$\mathrm{La} / \mathrm{SSB}$, were not associated with early-onset ELN. Erythrocyte sedimentation rate (ESR) was significantly lower in CSLE with ELN compared to those without ELN $(p=0.02)$. We found no statistically significant difference in other major organ involvement in those with ELN compared to those without ELN. Only statistical trend was observed in the comparison of neuropsychiatric manifestations in those with ELN, tested by chi-square test $(p=0.06)$.

Further analysis of these patients, during the last follow-up, revealed that death rates were significantly higher in the group with ELN $(p<0.0001)$. Overall cSLE median follow up time was nearly four years; it 
was comparable between those with and without ELN (Table 1). SLICC-DI scored during the last follow up visit had significant difference, being higher in those with $\operatorname{ELN}(p=0.004)$.

\section{Discussion}

This large multicenter study confirms and expands the findings of previous reports ponting to lupus nephritis as a relevant feature of cSLE. It further demonstrates that ELN is characterized by high frequency arterial hypertension, hematuria proteinuria, low $\mathrm{C} 3$, anti-dsDNA and a significant proportion of acute renal failure. It is in keeping with recent reports comparing renal involvement in cSLE versus adult onset SLE $[14,15]$. The clinical picture mostly likely represents proliferative glomerular lesions. In fact, more than half of the patients had class III to V by WHO classification categories. This is in accordance with former case series reports, from different ethnic backgrounds populations. Comparable death rates and endstage renal disease were also seen $[2,3,14]$.

Our study contributes to the current knowledge of ELN in cSLE, reflecting in accrued damage, scored by SLICC damage index and mortality. In our series and previous reports, ELN is a predominant feature of cSLE, in particular when compared to adult series [14, 15]. ELN was confirmed by a comprehensive assessment of standardized clinical and laboratory measures, in a large multicentric study, from a population of mixed ethnic background, where non-Caucasians had higher frequency of ELN.

The role of complement as biomarker of ELN was explored. Complement and immunoglobulin deposition is a characteristic finding in ELN renal biopsies and low serum $\mathrm{C} 3$ and $\mathrm{C} 4$ have been considered as disease activity biomarkers. But, it was rarely reported in pediatric patients $[7,16,17]$. Activation of the classical complement system by immune complex contributes to inflammation and tissue injury. However, the measurement of C3 and C4 serum levels has several drawbacks. The range of $\mathrm{C} 3$ and $\mathrm{C} 4$ in the normal plasma is wide, consumption during activation can lead to increased synthesis due to acute phase reaction, resulting in no net change. Although complement serum levels do not differentiate between consumption and production, they are used worldwide for assessing lupus activity.

Our study has the limitations of a retrospective assessment, diagnosis delay or limitation of obtaining renal biopsy, as well as classifying those renal biopsies in different centers and also limited resources for laboratory tests as $\mathrm{C} 3, \mathrm{C} 4$ and $\mathrm{CH} 50$ determination. Other study limitations were those of retrospective assessments where new biomarkers were not studied. Also, the longitudinal comparison of final renal outcome as association with chronic renal failure, dyalisis and transplantation could not be addressed in this sample, but there is work is in progress in the expanded database, addressing this research question. In spite of these caveats, paired comparison between those presenting with ELN and without ELN was possible in a robust sample, in a series with a medium follow up time of four years.

\section{Conclusion}

The frequency of ELN was 50\%, it was predominant in non Caucasians and resulted in higher morbidity and mortality. The urinary parameters, positive anti-dsDNA and low $\mathrm{C} 3$ are practical and reliable biomarkers, for discriminating ELN.

\section{Acknowledgements}

DF Miguel is undergraduate FAPESP scholar (2016/09092-3). We thank all contribution from all 27 Pediatric Rheumatology members of the Brazilian Childhood-onset Systemic Lupus Erythematosus Group and to the UNESP research office (EAP) at Botucatu Medical School.

Authors' contributions

All the authors provided substantial contribution to the study design, data acquisition, analysis, data interpretation and final approval of the manuscript.

Authors information

Not applicable.

\section{Funding}

It was provided by the authors institutions and the following scholarships FAPESP 2016/09092-3 and CNPq 303752/2015-7, 301805/2013-0, 305068/ 2014, 303422/2015-7, 301479/2015.

Availability of data and materials

The authors can provide all the source data and analysis.

Ethics approval and consent to participate

It was granted as a national multicentric protocol under n 264.656/CAAE 09231912.2.2003.541 on May 6th 2013

Consent for publication

It was given according to ethical standards and authorship policy.

\section{Competing interests}

The authors declare that they have no competing interests.

\section{Author details}

${ }^{1}$ Universidade Estadual Paulista (UNESP) Faculdade de Medicina de Botucatu, Botucatu, Brazil. ${ }^{2}$ Pediatric Rheumatology Division, Faculdade de Medicina de Botucatu, Universidade Estadual Paulista (UNESP), São Paulo, Brazil. ${ }^{3}$ Rheumatology Division, Hospital das Clinicas HCFMUSP, Faculdade de Medicina, Universidade de São Paulo, São Paulo, Brazil. ${ }^{4}$ Children's Institute, Hospital das Clinicas HCFMUSP, Faculdade de Medicina, Universidade de São Paulo, São Paulo, Brazil. ${ }^{5}$ Biostatistic Department, Instituto de Biociencias, Universidade Estadual Paulista (UNESP), Botucatu, Brazil. ${ }^{6}$ Pediatric Rheumatology Division, Faculdade de Medicina de Botucatu, Universidade Estadual Paulista (UNESP), Botucatu, Brazil.

Received: 5 September 2019 Accepted: 19 January 2020

Published online: 01 February 2020

\section{References}

1. Hiraki LT, Benseler SM, Tyrrell PN, Hebert D, Harvey E, Silverman ED. Clinical and laboratory characteristics and long-term outcome of pediatric systemic lupus Erythematosus: a longitudinal study. J Pediatr. 2008;152:550-6.

2. Hiraki LT, Lu B, Alexander SR, Shaykevich T, Alarcon GS, Solomon DH, Winkelmayer WC, Costenbader KH. End-stage renal disease due to lupus 
nephritis among children in the US, 1995-2006. Arthritis Rheum. 2011;63: 1988-97.

3. Frankovich JD, Hsu JJ, Sandborg Cl. European ancestry decreases the risk of early onset, severe lupus nephritis in a single center, multiethnic pediatric lupus inception cohort. Lupus. 2012;21:421-9.

4. Lee PY, Yeh KW, Yao TC, Lee WI, Lin YJ, Huang JL. The outcome of patients with renal involvement in pediatric-onset systemic lupus erythematosus--a 20-year experience in Asia. Lupus. 2013;22:1534-40.

5. Wu JY, Yeh KW, Huang JL. Early predictors of outcomes in pediatric lupus nephritis: focus on proliferative lesions. Semin Arthritis Rheum. 2014;43:513-20.

6. Smith EMD, Lewandowski LB, Jorgensen AL, Phuti A, Nourse P, Scott C, Beresford MW. Growing international evidence for urinary biomarker panels identifying lupus nephritis in children - verification within the south African Paediatric lupus cohort. Lupus. 2018;27:2190-9.

7. Wakiguchi H, Takei S, Kubota T, Miyazono A, Kawano Y. Treatable renal disease in children with silent lupus nephritis detected by baseline biopsy: association with serum C3 levels. Clinical Rheumatol. 2017;36:433-7.

8. Gomes RC, Silva MF, Kozu K, Bonfa E, Pereira RM, Terreri MT, Magalhaes CS, Sacchetti SB, Marini R, Fraga M, et al. Features of 847 childhood-onset systemic lupus erythematousus patients in three age groups at diagnosis: a Brazilian multicenter study. Arthritis Care Res. 2016;68:1736-41.

9. Gladman DD, Ibanez D, Urowitz MB. Systemic lupus erythematosus disease activity index 2000. J Rheumatol. 2002;29:288-91.

10. Sutton EJ, Davidson JE, Bruce IN. The systemic lupus international collaborating clinics (SLICC) damage index: a systematic literature review. Semin Arhritis Rheum. 2013:43:352-61.

11. Chan JC, William DM, Roth KS. Kidney failure in infants and children. Pediatric Rev. 2002;23:47-60

12. National Kidney Foundation K/DOQI clinical practice guidelines for chronic kidney disease: evaluation, classification, and stratification. Am J Kidney Dis Suppl 2002, 39:S1-S266.

13. Marks SD, Sebire NJ, Pilkington C, Tullus K. Clinicopathological correlations of paediatric lupus nephritis. Pediatr Nephrol. 2007;22:77-83.

14. Ambrose N, Morgan TA, Galloway J, Ionnoau Y, Beresford MW, Isenberg DA. Differences in disease phenotype and severity in SLE across age groups. Lupus. 2016;25:1542-50.

15. Bundhun PK, Kumari A, Huang F. Differences in clinical features observed between childhood-onset versus adult-onset systemic lupus erythematosus: a systematic review and meta-analysis. Medicine. 2017;96:e8086.

16. Ting CK, Hsieh KH. A long-term immunological study of childhood onset systemic lupus erythematosus. Ann Rheum Dis. 1992;51:45-51.

17. Lewandowski LB, Schanberg LE, Thielman N, Phuti A, Kalla AA, Okpechi I, Nourse P, Gajjar P, Faller G, Ambaram P, et al. Severe disease presentation and poor outcomes among pediatric systemic lupus erythematosus patients in South Africa. Lupus. 2017;26:186-94.

\section{Publisher's Note}

Springer Nature remains neutral with regard to jurisdictional claims in published maps and institutional affiliations.

Ready to submit your research? Choose BMC and benefit from:

- fast, convenient online submission

- thorough peer review by experienced researchers in your field

- rapid publication on acceptance

- support for research data, including large and complex data types

- gold Open Access which fosters wider collaboration and increased citations

- maximum visibility for your research: over $100 \mathrm{M}$ website views per year

At $\mathrm{BMC}$, research is always in progress.

Learn more biomedcentral.com/submissions 